ESDA2014-20539

\title{
ROTATIONAL MOLDING APPLIED TO THE MANUFACTURING OF BLADES OF SMALL WIND TURBINE
}

\author{
M. Dolores Marrero \\ University of Las Palmas \\ de Gran Canaria \\ Mechanical Engin. Dpt. \\ 35017 Las Palmas G.C. \\ Canary Islands. Spain
}

\author{
Pedro Hernández \\ University of Las Palmas \\ de Gran Canaria \\ Mechanical Engin. Dpt. \\ 35017 Las Palmas G.C. \\ Canary Islands. Spain
}

\author{
José Martín \\ 3IDS \\ Par. Cien.-Tecnológico \\ ULPGC \\ 35017 Las Palmas G.C. \\ Canary Islands. Spain
}

\author{
Luis Suárez \\ University of Las Palmas \\ de Gran Canaria \\ Mechanical Engin. Dpt. \\ 35017 Las Palmas G.C. \\ Canary Islands. Spain
}

\author{
David Pestana \\ University of Las Palmas \\ de Gran Canaria \\ Mechanical Engin. Dpt. \\ 35017 Las Palmas G.C. \\ Canary Islands. Spain
}

\begin{abstract}
The small wind energy produces electric energy using power turbines below $100 \mathrm{~kW}$. This technology allows the electrical supply in places isolated, generates energy of way distributed (distributed microgeneration) and permits to produce electricity in the points of consumption. The rotomoulding process is characterized to allow hollow plastics parts, with great surface quality, good homogeneity of thicknesses and suitable mechanical properties, all this with a great freedom of design and a wide variety of materials. The Department of Economy and Competitiveness from Government of Spain, inside the Subprogram INNPACTO 2012, resolved to grant the project of title Development of new blades made for rotational moulding for small wind generators (RotEos). The main purpose of this project is focused on getting a viable and cheaper process to manufacture the blades to small wind generators without reducing the efficiency of them, and trying to increase the competitiveness of these turbines. This research work presents the initial results obtained in the design of the blades, materials characterization and in the manufacturing process of these components.
\end{abstract}

\section{INTRODUCTION}

Wind energy is obtained from the kinetic energy generated by the effect of air currents and this energy is converted into other useful forms of energy for human activities. It is mainly used to produce electricity through wind turbines. The mini-

$\begin{array}{cc}\text { Silvia Rivero } & \text { Estela Calero } \\ \text { 3IDS } & \text { 3IDS } \\ \text { Par. Cien.-Tecnológico } & \text { Par. Cien.-Tecnológico } \\ \text { ULPGC } & \text { ULPGC } \\ \text { 35017 Las Palmas G.C. } & \text { 35017 Las Palmas G.C. } \\ \text { Canary Islands. Spain } & \text { Canary Islands. Spain }\end{array}$

wind turbines employ generators up to $100 \mathrm{~kW}$. In Spain, there have been realized diverse studies that try to stimulate this sector and they include from the design and manufacture of new wind generators to their legislative and regulatory aspects, including the characterization of the wind resource for the wind generators of small power and the development of their specific components. [1].

Inside this line of research, in 2012, the Department of Economy and Competitiveness resolved to grant the project of title Development of new blades made for rotational moulding for small wind generators (RotEos), whose main objective is to study the feasibility of manufacturing the mini-blades for the rotational moulding process. The partners of this project are: Ingeniería, Investigación e Innovación para el Desarrollo Sostenible (3IDS), Obeki Group (OBEKI) and Procesos de Fabricación research group at Universidad de Las Palmas de Gran Canaria (ULPGC).

The rotomoulding process is characterized to allow hollow plastics parts, with great surface quality, good homogeneity of thicknesses and suitable mechanical properties, mainly due to low or no existence of internal stresses. Also, it is a technology that allows great freedom to create, functionality and complexity of design, at the same time that allows working with a broad variety of materials. [2-4] 
It is necessary to highlight, as reference, it can be considered that the manufacturing costs of the blade generally represent between $10 \%$ and $15 \%$ of the total cost of the turbine, hence the importance of studying new manufacturing processes that allow reducing these costs.

Definitively, the scope of the project is focused on raising a blade manufacturing strategy of small wind turbines designed to define an advanced, alternative and mass production method thereof, since current manufacturing processes mini-turbines blades are very laborious and craft. It seeks to provide faster, lower costs and increased repeatability, uniformity and quality.

The research presented here shows the first results obtained in the initial stages of development of the aforementioned project.

\section{EXPERIMENTAL}

The experimental stage of the process began checking the features that should meet the demonstrator manufacturing element. After studying different commercial profiles, was chosen the one that offered more interior volume to facilitate manufacturing by rotomoulding. The selected profile to realize the prototype blade was NREL's S822 Airfoil. Specifically, it was established to manufacture a rotomoulded blade about $2 \mathrm{~m}$ in length in an aluminium mould.

The aerodynamic calculation started with a pre-design to obtain the optimum geometry of the blades (chord and twist along their entire length), without regard to their profile, so that would capture the maximum power for an operating conditions determined in function of an estimated average wind speed (6 $\mathrm{m} / \mathrm{s}$ ), a number of blades at wind generator (3), an estimated power one $(<100 \mathrm{~kW})$ and a specific speed.

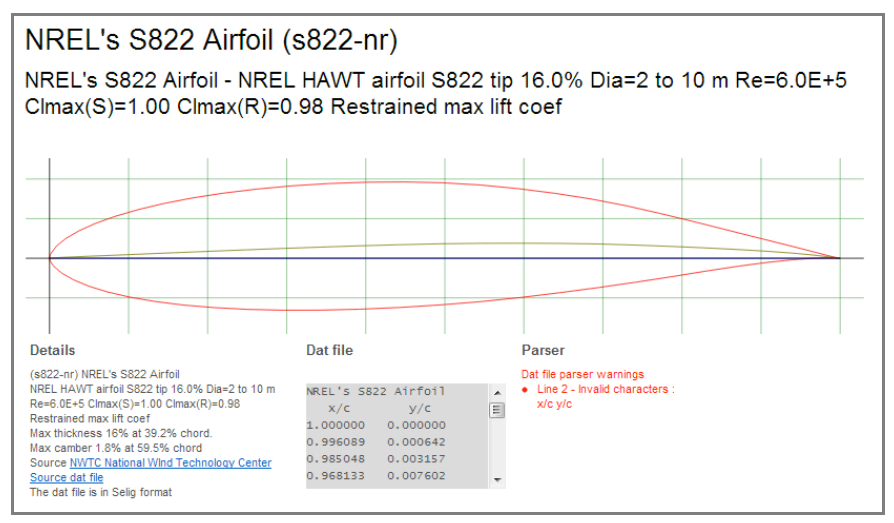

Figure 1: Profile NREL's S822.

However, during the course of the investigation the initial geometry was changed to be adjusted the manufacturing process and to ensure its strength, so that the definitive profile, although it is based on this model, does not coincide exactly with them.

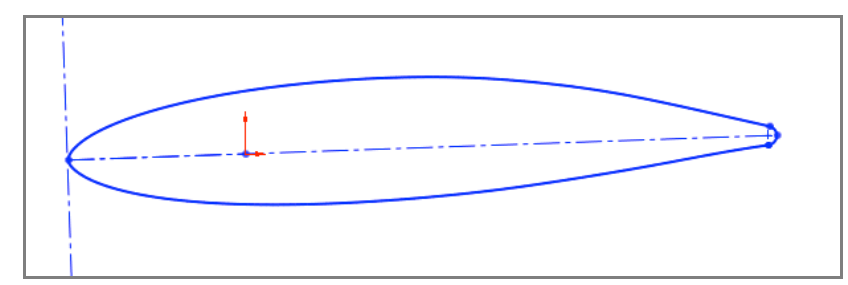

Figure 2: Adapting the profile selected for their suitability to the manufacturing process for rotational molding.

The used computer applications were Solidwork Premium and Solidwork Simulation, as well as DICAP-3iDS, software that allows determining, between others parameters, the one of dragging and lift coefficient of the blades depending on the attack angle and the Reynolds number.

The same methodology was followed in the field of materials, that is, initial use of materials used in rotomoulding process in powder and commercial format, which provides information about its operating parameters, distribution of particle size, ranges of apparent density (bulk density), powder flowability, etc.

Although it has not been found any reference to the manufacturing of blades rotational molded for a small wind turbine, there are several research have proposed the use of composites materials for manufacturing turbine components [58].

The final materials for the manufacturing of prototype blade would be selected from the experimental tests on a small mould, also aluminium, and tested in an experimental rotational moulding machine. This machine was designed and manufactured at the University of Las Palmas de Gran Canaria.

The commercial materials of rotomoulding initially proposed were polyethylene, crosslinked polyethylene and polypropylene. Also, it was proposed a mix of commercial polymeric materials of different types (thermoplastics, resins, reinforcements, etc.), which included mono and multilayer solutions and assessing the use of reinforcements, preferably natural ones. We are currently analyzing what would be the appropriate methodology for incorporating different combinations of materials in the rotational mould for their proper operation (introduction order, presence of cores, inserts, use of reinforcement, compatibilizers, etc.).

It also began to work on analytical simulations using the computer application RotoSim. This program sets the optimal processing conditions and thickness distributions and temperature profiles in the rotomoulded parts. Initially it was worked with the cubic mould initially designed and manufactured for the study of behaviour of selected materials. Later, it was simulated several profiles sections in order to obtain information about the experimental rotational moulding process parameters. These analytical parameters were 
subsequently used as guidance work parameters employed in performing experimental testing.

As an example the Figure 3 shows the temperature profiles of the mold, indoor air and power during rotomoulding process with HDPE.

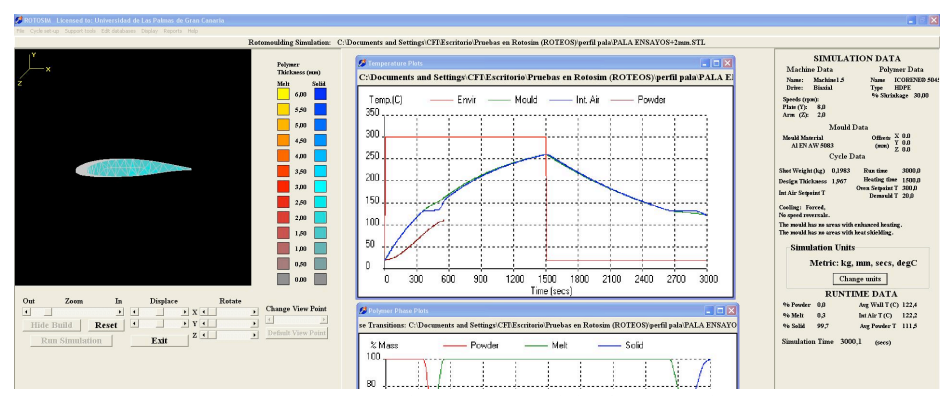

Figure 3. RotoSim simulation of a blade profile section.

\section{RESULTS}

For the initial design of the blade the following parameters were used:

Root angle: $10^{\circ}$

Root chord: $360 \mathrm{~mm}$

Tip angle: $2^{\circ}$

Tip chord: $180 \mathrm{~mm}$

Blade length: $2.388 \mathrm{~mm}$

The material used in the simulated load of the blade was a copolymer of the following features:

Modulus of elasticity: $1100 \mathrm{MPa}$

Poisson coefficient: 0.4103

Mass Density: $900 \mathrm{~kg} / \mathrm{m}^{3}$

Limit of elasticity: $24 \mathrm{MPa}$

For these first analysis must be considered that the blade was completely solid, still knowing the impossibility of reproducing this circumstance in the rotational moulding process. The target was to validate resistant capacity the polymer solution adopted.

To evaluate the loads applied to the blade, it was used as reference the recommendations of IEC 61400-1, where parameters include wind speed for different kinds of wind conditions. The most unfavourable considered simulation was of hurricane winds at $50 \mathrm{~m} / \mathrm{s}$ and stopped rotor, that was performed by applying an axial load of $1375 \mathrm{~N}$ and other tangential of $250 \mathrm{~N}$ distributed along the entire blade (See Figure 4).
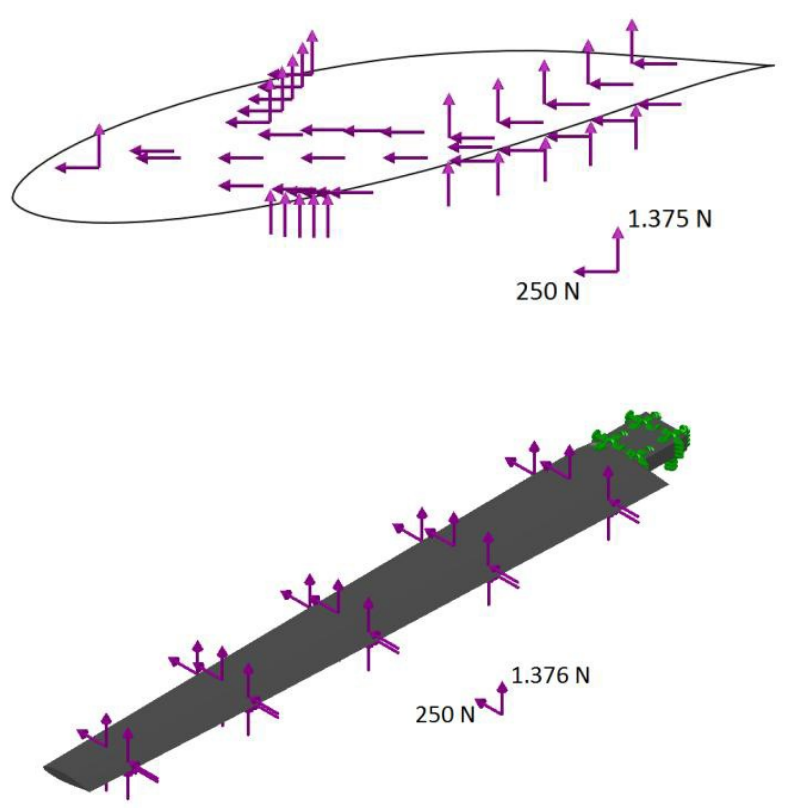

Figure 4. Distribution of the most unfavourable load assumptions used in the analytical study.

Load tests carried out on a blade in these conditions resulted in the need to add reinforcements to the polymer structure that would ensure the resistant behaviour of the same, due to the applied loads caused a deflection in peak (arrow) excessive, confirming the need to use reinforcements in order to stiffen the whole polymer.

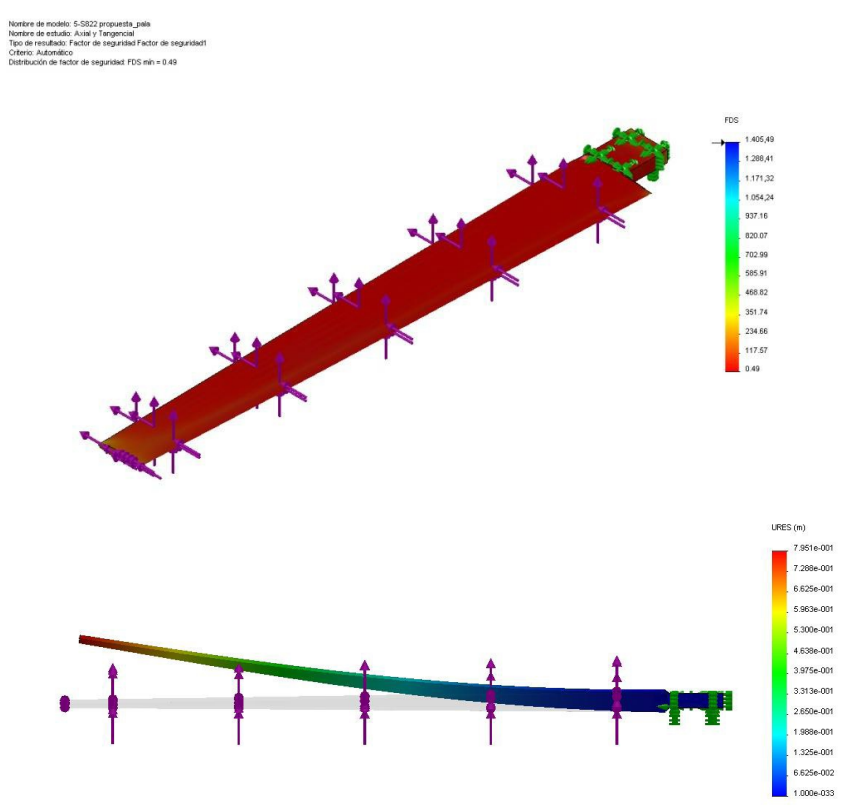

Figure 5. Load analysis results under the conditions described in the text. 
Experimental tests in laboratory rotational moulding machine were initiated with the selected materials named above. Assuming that the resistant simulation had demonstrated the need of use reinforced polymers, experimental test was initiated with rotomoulded parts structured in bi-component layer.

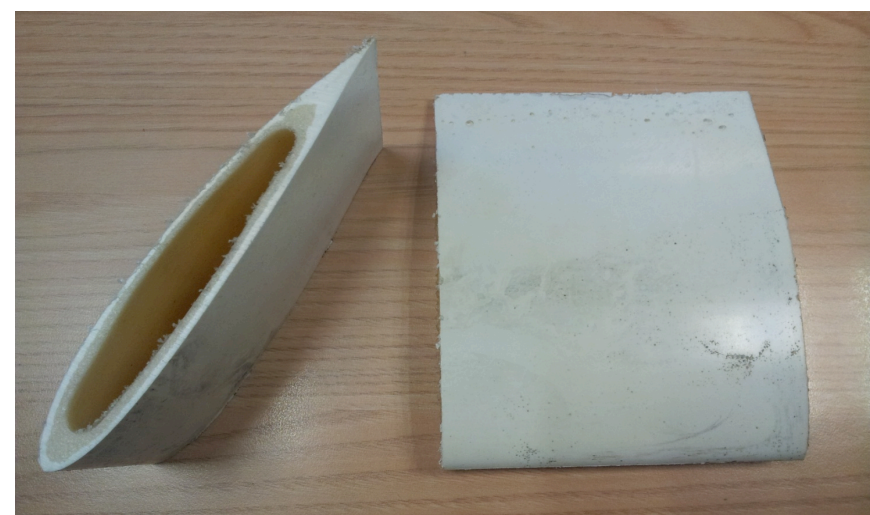

Figure 6. Rotomoulded parts with polymeric materials originally proposed.

After analyzing the results of simulations of load and once concluded the need to add additional elements to increase the resistance of the blades, the tests were continued in the cubic geometry aluminum mould to analyze the flow of material with the presence of additional elements inside: fibres (Figure 7 and 8 ) or metallic elements (See Figure 9).

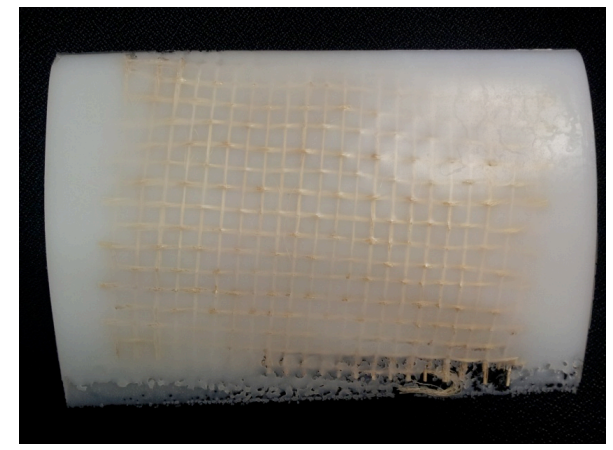

Figure 7. Rotomoulded part reinforced with Canarian banana fibre.

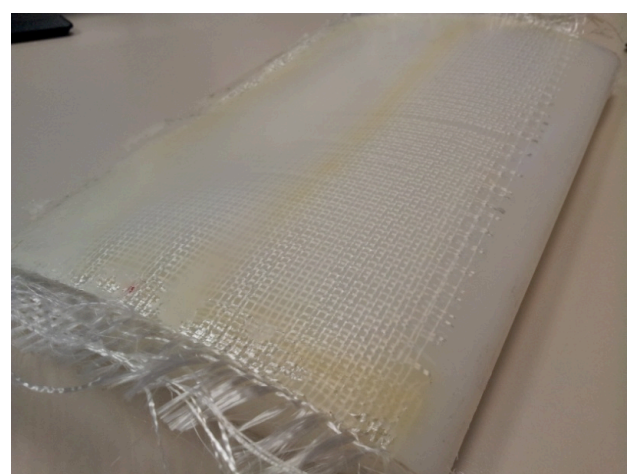

Figure 8. Rotomoulded part reinforced with fibre glass.
Metal reinforcements were used like stiffeners of the blade and it was studied their geometry and location to ensure proper operation during the manufacturing process. It was placed inserts that increase the rigidity of the assembly and also do not impede the flow of material inside during the rotational moulding process. This is studied both analytically and experimentally, different options, some of which are shown in the following images:

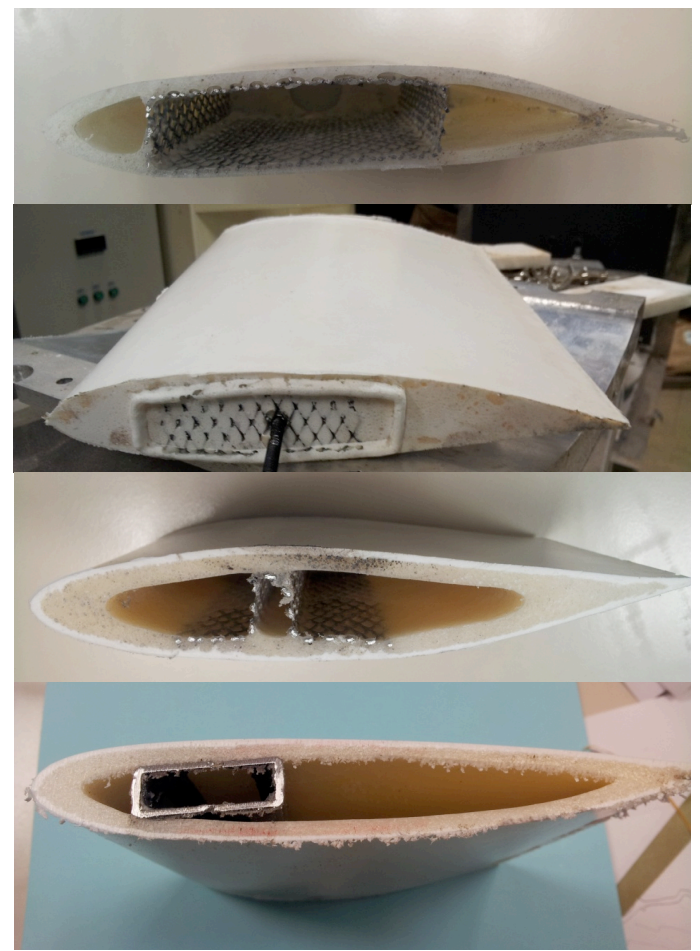

Figure 9. Rotomoulded parts reinforced with metal inserts of different shapes and location.

The results allowed concluding that rotomoulded part was more resistant with the use of both fibre and metal elements. However, the presence of metallic elements proved to be most suitable from the point of view resistant and adaptation rotomoulding process.

Although the best solution is currently being studied, it appears that the blade will finally be constituted by a polymeric shell and an inner metal reinforcement to ensure the strength of the assembly.

In turn, this element must be inside of the blade, and should not change its shape or create difficulties in performing the part by rotational molding. Therefore, it has chosen a conical hollow member that was easy to make, durable and they occupy the largest possible volume inside the blade. 


\section{CONCLUSIONS}

Experimental trials carried out so far for validating the rotational moulding process as suitable for use in the manufacture of small wind turbines blades.

However, it appears that the exclusive use of polymeric materials characteristic of this process is not enough to present the resulting part -resistant capacity is required in service.

For this purpose, initially, and although this study has raised standard blade profile, have adapted these to their suitability for the rotational moulding process.

Furthermore, it has been proposed the use of metal elements to reinforce the joint and do not prevent the normal flow of the powder during the rotational moulding.

In short, and although the results are still scarce, early trials suggest that it is feasible to manufacture mini-turbine blades by using commercial materials in rotational moulding sandwich structure reinforced with metal inserts to ensure the strength characteristics of blades.

\section{ACKNOWLEDGEMENTS}

This project has been approved by the Department of Economy and Competitiveness, from Government of Spain, inside the Subprogram INNPACTO 2012.

This work was supported by OBEKI.

\section{REFERENCES}

1. Plan de Energías Renovables, Vol. 1, Ministerio de Industria, Turismo y Comercio, (2011).

2. Roy J. Crawford, Mark P. Kearns. Practical Guide to Rotational Moulding. Rapra Technology Limited, (2003).

3. R. J. Crawford. Rotational Moulding of Plastics, John Wiley \& Sons Inc. New York, (1996).

4. Glenn L. Bell. Rotational Molding. Design, Materials, Tooling and Processing, Hanser, Munich, (1998).

5. C. Monroy Aceves, M.P.F. Sutcliffe, M.F. Ashby, A.A. Skordos, C. Rodriguez Roman. Design methodology for composite structures: A small low air-speed wind turbine blade case study, Materials and Design 36, pp. 296-305 (2012).

6. J. Zangenberg, P. Brøndsted, M. Koefoed. Design of a fibrous composite preform for wind turbine rotor blades. Materials and Design 56, pp. 635-641 (2014).

7. Peng-Cheng Ma, Yi Zhang. Perspectives of carbon nanotubes/polymer nanocomposites for wind blade materials. Renewable and Sustainable Energy Reviews 30, pp. 651-660, (2014).

8. C. Astle, I. Burge, M. Chen, T. Herrler, L. Kwan, N. Zibin, D. Wood. Timber for small wind turbine blades, Energy for Sustainable Development 17, pp. 671-676, (2013). 